\title{
Organic Chemists of Pre-Independence India: With Special Focus on Natural Products
}

\author{
D Balasubramanian*
}

(Received 17 May 2018; revised 22 June 2018)

\begin{abstract}
Using materials obtained from plants and animals for medicinal, community and technical purposes has been going on in Indian and other ancient civilizations for millennia. With the introduction of western scientific methods into colonial India, isolating, purifying and determining the chemical structures of the components in these materials, and some understanding of the basis of their action became possible. We focus here on the birth and growth of the chemistry of natural products of medicinal and technical value. We discuss here the roles of three pioneers in organic chemistry who started their work in colonial India and enabled the blossoming and growth of outstanding research the field, once the colonial bondage was freed: Professors T R Seshadri, who was single-handedly responsible in generating excellent schools of medicinal products chemistry across the country, K Venkataraman who catalyzed many Indian-initiated chemical industries through his research and mentorship, and Salimuzzaman Siddiqui, who became the father of organic chemistry as well as modern scientific research in Pakistan in particular.
\end{abstract}

Key words: Dyes, Foundations of science in Pakistan, Molecular structure, Natural products, Seshadri, Salimuzzaman Siddiqui, Venkataraman.

\section{INTRODUCTION}

We have purposely chosen to write about organic chemistry and its famous practitioners in colonial (pre-Independence) India rather than other equally famous inorganic and physical chemists, or for that matter the whole field of chemistry, because (a) India has had a long continuing history of the study of materials from plants and trees, animals and humans, and marine sources (called natural products), particularly for medicinal uses (through the Ayurveda, Siddha, Unani, tribal and the western systems, e.g., Valiathan, 2013; NIIR Board of Consultants, 2003; Mao, Hynniewta and Sanjappa, 2009; Shankar, Lavlekar, Deb and Sharma, 2011), industrial and community uses (such as dyes, paints oils and gums), and (b) several of its practitioners had a sense of national pride, and often also pursued other areas of culture such as arts, literature and poetry, and spiritualism.

K Nagarajan has published an outstanding history of natural products research in India during the last century (Nagarajan, 2014), but we wish to focus on three pioneers in the field, each having nurtured and mentored a large number of students who themselves have since contributed to the growth and development of the field, and the intellectual and industrial advancement of the nation. The three are (a) Professor T R Seshadri, (b) Professor K Venkataraman and (c) Professor Salimuzzaman Siddiqui. Since the memoirs of the first two are available in details in the INSA library, we will be brief about them. However, we need to discuss a little more about Professor

\footnotetext{
* Distinguished Scientist \& Director of Research Emeritus, LV Prasad Eye Institute, Hyderabad 500034, Email:dbala@lvpei.org
} 
Salimuzzaman Siddiqui, who went beyond the laboratory and played a role in advancing science itself in colonial India, free India and Pakistan.

\section{Doing Organic Chemistry in Classical Ways}

On an aside, it is important to point out here that research in the area of organic chemistry those days was quite daunting. No methods of spectroscopy that would dig deep into the structures of molecules and the bonding pattern of atoms within it were available. One had to first obtain kilograms of the material in which the natural product of interest was but one component, find methods to successfully isolate and purify it using methods available at that time. Once obtained in the purest possible form, one needed to determine its molecular weight by the best available method, then break the molecule down and determine the types and numbers of the various constituent atoms $(\mathrm{C}, \mathrm{H}, \mathrm{N}, \mathrm{O}, \mathrm{P}, \mathrm{S}$ and others) in it and, using the methods of chemistry, decide which atom is bound to which and so forthand come out with a possible structure of the molecule. Once an idea of the possible structure is obtained, one now had to go ahead and make it (synthesize) in the laboratory. This is somewhat similar to first isolating a Lego set or a 3dimensional jigsaw puzzle from a mixture of other materials, take it apart, and then put all the components back to make the original. To study just one molecule this way could take several years, often a whole $\mathrm{PhD}$ thesis. Indeed it is not for nothing that this entire exercise been described as an art form. It was with this in mind that the late Professor S Ranganathan wrote a book called the Art in Organic Synthesis (Anand, Bindra and Ranganathan, 1970). With advancements in the area of spectroscopy and newer methods of isolation and purification, what took 5-10 years those days can be done within 5 months or so today.

\section{Start of the Use of Western Science on Natural Products Chemistry: The PIONEERS}

One of the earliest to work on plant products in India was Sir John L Simonsen, who served at the Presidency College, Madras (191018), the Indian Institute of Science, Bangalore (1918-28), and the Forest Research Institute, Dehra Dun before returning to England. His finding that 3-carene was the major constituent of Indian turpentine and his isolation of longifolene from Pinus longifolia Roxb were important contributions. In England he became one of the leading organic chemists of his generation, recognized for his extensive work on the chemistry of terpenoids (Nagarajan, 2014).

The next was Biman Bihari Dey, who came back from Aberdeen to Presidency College, Madras (1920-44), and taught two outstanding students, namely, T R Seshadri and K Venkataraman during their early careers. Dey was an expert in plant product chemistry, and isolated and determined the chemical structure of the molecule toddalinine, isolated from forest pepper. (For a biographical memoir of Dey, please see $<$ www.insaindia.res.in/BM/BM1_6603.pdf>).

Note that the great master P C Ray of Presidency College Calcutta and Calcutta University was mainly an inorganic chemist, with little contribution in the area of organic chemistry and in natural products. However, he did make thiocamphor, dithian and sulphones (Goswami \& Bhattacharya, 2001).

Due credit should be given to Ramnath Chopra, who has been called the 'Father of Indian pharmacology'. He was the first to establish a centre of study and research in pharmacology in India, at the Calcutta School of Tropical Medicine (1921-41). His research was focused on various indigenous drugs like ispaghula, kurchi, rauwolfia, psoralea, cobra venom, and others (Singh, 2009). 
Turning to the 1930 s, we come to a great organic chemist, P C Guha, who taught at the Indian Institute of Science, Bangalore during 1928- 53, specializing in essential oils. He was the mentor of two great organic chemists of more recent times, namely, Drs. S C Bhattacharyya and Sukh Dev, each of whom mentored some notable and contemporary organic and natural product chemists themselves. At about the same time P K Bose taught at the University of Calcutta and the Bose Institute, during 1930-1950. His field was phytochemistry and synthetic organic chemistry. During these twenty years, he mentored dozens of students, most notably Professor Asima Chatterjee. A special mention must be made about her, since she was the first woman to receive a Doctorate of Science from an Indian university (in 1944 from the Calcutta University), and in her career that spanned over three decades, she conducted research on vinca alkaloids, the development of anti-epileptic drugs, and development of anti-malarial drugs. She also authored a considerable volume of work on medicinal plants of the Indian subcontinent (De, 2015).

We now turn to three important scientists practicing organic chemistry, who have played vital roles in putting India (and Pakistan) on the world map, in the field of not just organic chemistry, but chemistry itself. These three are Professors T R Seshadri, K Venkataraman and Salimuzzaman Siddiqui. Seshadri was a master of masters, having guided as many as 150 doctoral students and published 1200 research papers in his career of over four decades, thus assuring the vibrant growth of the field across India,

Venkataraman focused his organic chemical research towards the growth of chemical technology and the initiation of a significant number of chemical and dyestuff companies in India. Salimuzzaman Siddiqui, after doing remarkable natural product chemistry in India, moved to the newly created country, Pakistan, set up not only a research culture there, but also helped establish scientific institutions in the western and eastern regions of the new nation.

\section{Professor T R Seshadri}

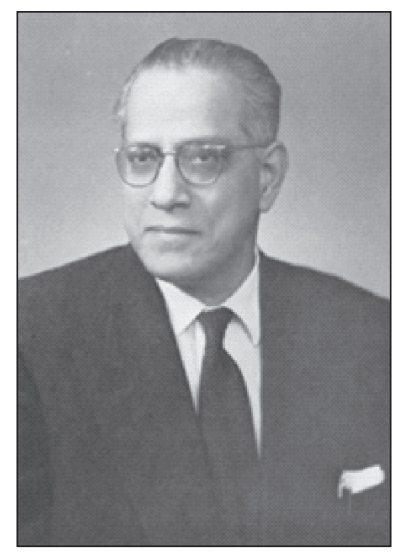

Born in 1900, Seshadri was associated with the Ramakrishna Mission since his school days, and a strict follower of the Mission's ideals till his passing away. He had worked for the Mission for a year, helping them organize a school before he obtained a University Research Scholarship. He used this to join Presidency College, Madras. Here, he worked as a research scholar under Dey and won prizes for his research, leading to his obtaining the Government of Madras Overseas Scholarship. He used it to go to Manchester, UK to work with Sir Robert Robinson (an outstanding and highly respected organic chemist of that era, who was awarded the Nobel Prize in Chemistry 1947 'for his investigations on plant products of biological importance, especially the alkaloids'). In 1930, when he returned from UK to India, the country was caught in the most severe economic depression. This made him jump from job to job, in a rather peripatetic manner, moving from Coimbatore to Madras, Waltair (Visakhapatnam) and then on to Delhi University in free India in 1949, upon the invitation of the then Vice Chancellor Gwyer, where he stayed and worked until he passed away in 1975. At each city, he attracted and mentored students, expanded the scope of his research, discovered and synthesized 
new molecules from Indian natural sources. And as new methods of analyzing molecular structures and synthesizing molecules were developed, he mastered them, keeping himself and his lab upto-date.

Seshadri was a master in the art of organic synthesis. An excellent summary of his work has been published (Krishnaswamy, 2004). Thus, we need not write much on the outstanding contributions of TRS except to state that if there was one man at that time whom you can single out as the most prolific researcher and mentor anywhere, in the area of natural products chemistry, it would be Professor Seshadri. During his long career, he published a total of over 1200 research publications and guided $150 \mathrm{PhD}$ students, a feat not bettered by many even today. He was truly a giant, who showed us what many vitamins are made of, what coumarins are, which molecules are good against malaria and other diseases. More than anything else, he has made India a vibrant centre for organic chemical research and development. He was elected Fellow of all science academies of India, was the President of INSA, Fellow of the Royal Society (FRS), of the German Academy of Sciences Leopoldina, and a Padma Bhushan awardee.

Despite all this, his last years were poignant. All he wanted to do was to practice organic chemistry, not become a Vice Chancellor, Chairman of the University Grants Commission and such. But the university rules changed in 1972 , and he could not continue in his position or the lab, nor guide students since he was 'old'. Neither could he be accommodated in any of the government labs nor obtain research grants. Depressed, he suffered heart attacks and passed away within 3 years, in 1975. As the eminent physicist scholar Dr. Atma Ram wrote:

We have in India the example of a scientist like TR Seshadri, who could not see eye to eye with the governmental scientific organizations in their manner of functioning, and was critical of the politician's interference and overlordship over scientific bodies, being singularly isolated to the extent that he had to undergo considerable suffering and die in penury (Atma Ram, 1978).

Has the situation changed today?

\section{Dr. K Venkataraman}

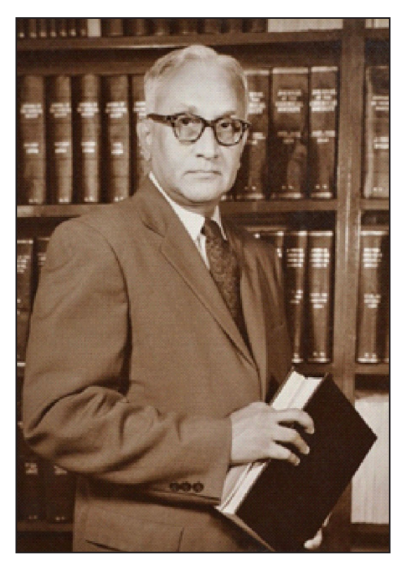

Turning to his contemporary and friend $\mathrm{K}$ Venkataraman (KV, 1901-81), his student Nitya Anand (himself a great medicinal chemist) has written a memoir about him, again available at INSA (Nitya Anand, 1981). Thus we do not have to elaborate much. Venkataraman too came from the Madras State, and from a distinguished family. His father, a Sanskrit Scholar, translated Vālmik̄ Rāmāyanam into Tamil. His elder brother compiled the collected works of Mahatma Gandhi, and his younger brother, Sanjeevi, a Professor of Medicine and an expert on TB, started the Voluntary Health Service system in Madras (which still continues). He himself was no less and his passion (as his later career proved) was to promote technology and industry, particularly in the area of chemicals, medicinal products and dyestuff. He too trained at the Presidency College Madras, under Professor Dey (thus becoming a contemporary of Seshadri) through a Madras Government Scholarship. He too went over to work with Robert Robinson, using an overseas scholarship. Returning to India in 1927, he first taught chemistry at the Foreman Christian College, Lahore (1928-34). Here he devised a very 
important chemical method for synthesizing flavones, chemicals that form the basis for a number of white and yellow pigments and dyes. He devised a novel method of molecular transformation which helped make flavones, and published it in 1934. About the same time one W Baker too published the same method; thus the method has come to be known as the 'BakerVenkataraman Transformation' (Baker, 1933; Mahal \& Venkataraman, 1934). ${ }^{1}$ Organic chemists in India are proud even today about this named method (please see endnote). He moved in 1935 to the University of Bombay as a Reader in Dyeing and Printing in the newly created University Department of Chemical Technology (UDCT), which is now established as an outstanding independent university. Here, he blended basic science and technology, with emphasis on industrial problems, and mentored many chemical/ dyestuff companies.

When new spectroscopic and crystallographic methods were being discovered and applied for determining structures of molecules, he took to them with vigour, and equipped the National Chemical Laboratory (NCL, Pune) where he moved as its Director in 1957, thus modernizing the practice of chemistry in India. He was an authority in the field of dyestuffs and published a 8-volume series named The Chemistry of Synthetic Dyes, and edited The Analytical Chemistry of Synthetic Dyes, which continue to be standard reference books in the field even today (Venkataraman, 1952-74; Venkataraman, 1977).

He was a great proponent of self-reliance, and opposed the import of technology wherever domestic knowhow was available ("Make in India'!). He pushed basic scientists to interact and work with industrialists and start-ups, which helped India become a major source of dyestuff and chosen medicinal compounds. This tradition has continued to this date by several of his students, notably Nitya Anand, MM Sharma, RA Mashelkar, AV Rama Rao and GD Yadav; the industrialist Mukesh Ambani too is an alumnus of UDCT).

Venkataraman had a penchant for hard work and a strict time table. Until his last days, he was up in the lab at 9 AM and left at 7 PM. He was happiest with his students and colleagues, and did not hunger for nor relish government positions, or committees. As his student Nitya Anand writes in the INSA memoir, he was an inspiring teacher and set before his students and colleagues high standards and lofty ideals. He was elected Fellow of all science academies of India, of the USSR Academy of Sciences, of the Polish Acad Sci, and was also a Padma Bhushan awardee.

And as the poem 'Yousuf' says: 'As one lamp lights another, nor glows less, so nobleness enkindleth nobleness'. So is knowledge, and Seshadri and Venkataraman lit many others.

\section{Professor Salimuzzaman Siddiqui}

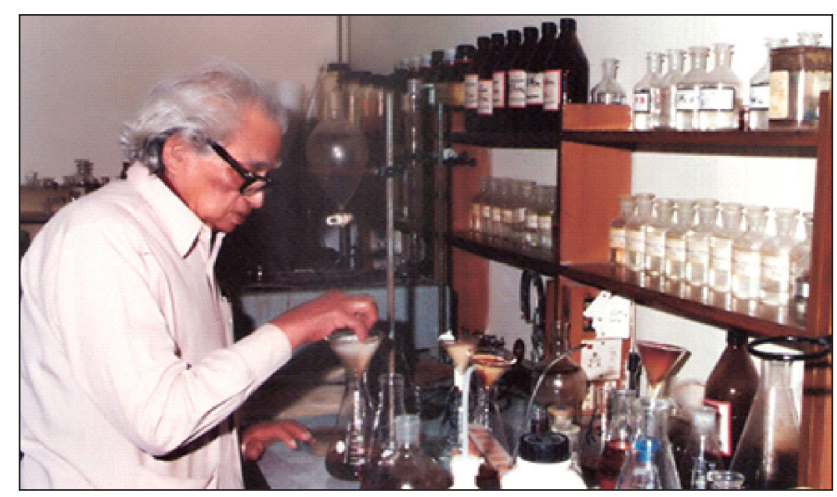

We now turn to a third remarkable contemporary of Seshadri and Venkataraman, namely Salimuzzaman Siddiqui, a great organic chemist of India and of Pakistan. While Seshadri was spiritually inclined and Venkataraman was essentially an ascetic, Siddiqui stands in contrast

\footnotetext{
1 Incidentally, at about the same time as the Baker-Venkataraman Transformation, two chemists from Calcutta, Drs. Jogendra Chandra Bardhan and Suresh Chandra Sengupta, had published a novel method to synthesize the aromatic compounds called phenanthrenes, and their methods is now referred to in literature as the 'Bardhan- Sengupta phenanthrene synthesis', a second 'name reaction' from India (Chakraborty and Saha, 2015). I thank the referee for alerting me on this.
} 
as an ebullient Renaissance Man. A colourful polyglot and polymath, he (1897-1994) was from Barabanki near the city of Lucknow, which was the cultural centre of Muslim India. Coming from a family of landlords, which had keen interest in literature, arts, calligraphy, painting (and alchemy!), he himself wrote poetry, translated Persian poetry into Urdu, and engaged in painting, all during his lifetime. His family wanted him to be a doctor and sent him to the Aligarh AngloOriental College (which later became Aligarh Muslim University) for his intermediate in science, but with his interest in philosophy and Persian literature, he ended up getting a degree in them! He then joined Grants Medical College in Bombay, passing its qualifying examination in 1919 . He was then sent to University College London for medical training, where he stayed until 1920.

His elder brother Khaliquzzaman Siddiqui, in a spirit of anti-imperialism, asked Salimuzzaman to leave Britain and move over to Germany to learn chemistry. The latter happily obeyed, since he wanted to be a chemist anyway, and joined the group of Julius van Braun at Frankfurt, and obtained his doctoral degree in 1927. (During these years, he also continued painting and took part in some exhibitions and won prizes and acclaim).

It was during this time that the Delhi-based famous practitioner of Unani traditional medicine, Hakim Ajmal Khan, got in touch with him and requested him to return to India, work at the Tibbia College, and conduct research into the chemical components of herbal medicinal plants; as an incentive, he offered Siddiqui the much-needed monthly stipend towards his stay in Germany. Siddiqui returned home and started his research first at the Indian Institute of Science in Bangalore, as the laboratories at Delhi were getting ready. Once they were, he moved to Delhi and set up research on three major plants. First, from Rauwolfia serpentina (snakeroot, or sarpagandha), he and his students isolated and characterized five alkaloids, each one of medicinal value, two brilli- ant yellow in colour, which he named as serpentine, serpentinine, and three colourless ones, named ajmaline, ajmalicine and ajmalinine (in honour of Hakim Ajmal Khan) (Siddiqui and Siddiqui, 1931, 1932, 1935). He also isolated a minor component named reserpine, which we now know to be a very powerful drug. From a second plant, Holarrhena antidysenterica (local names: kurai, kuteja, and Tellichery bark), he isolated and identified the drugs conessine, conarrhimine and others, and from the third, cassia absus (jashmejaz, or chaksushya) his group identified chaksine and isochaksine.

It was around 1945 that the government set up the Indian Council for Scientific and Industrial Research (ICSIR) in Calcutta, and Siddiqui was asked to go there and help in research, which he did. It was here that he researched on some of the active principles in the neem tree, and isolated the powerful anti-malarial drug named azadrachtin, and several other related compounds (Siddiqui, 1942). Another notable product he made at the ICSIR was an indelible ink, which is still used (both in India and Pakistan to identify every voter after he or she voted).

Then came Partition in 1947, dismembering India to produce West and East Pakistan, but Siddiqui did not move. When the then Prime Minister of Pakistan, Liaquat Ali Khan wrote to Prime Minister Nehru to persuade Siddiqui to move over to Pakistan, he went there to check the situation and came back telling Nehru that 'neither science nor arts exist in Pakistan'. Ultimately he did migrate to Pakistan in 1951 and settled down in Karachi, working at the University there and advising the government of Pakistan to set up the Pakistan Council for Scientific \& Industrial Research (PCSIR), the Pakistan Atomic Energy Commission, and set up research labs in Karachi, Lahore, Peshawar, Chittagong and Dacca. In 1966, when he turned 67, the PCSIR said that they would not extend his tenure for a $4^{\text {th }}$ term and without any prior indication, brusquely terminated his service (bureaucracy knows no partition). 
It was then that he moved to Karachi University, and with the help of a generous donor, he established the Husein Ebrahim Jamal (HEJ) Research Institute of Chemistry, with himself as Director and the then young Atta-Ur-Rahman as its Co-Director. This laboratory functions even today, doing some very good work and Atta-UrRahman continues to work there. It can rightly be said that Salimuzzaman Siddiqui laid the foundations for science and technology in the nascent country of Pakistan. He was rightfully honoured with every conceivable award of the country, including its highest, besides having been elected as an FRS, Foreign Fellow of INSA and other honours. A complete list of the research publications of Siddiqui can be found in the memoir written by M. Akhtar (1996).

\section{ACKNOWLedgements}

I am grateful to Drs. Nitya Anand, A V Rama Rao, K Nagarajan and S Rajappa for inputs and advice about Drs. Seshadri and Venkataraman, and to Professor Ata-ur-Rahman for his inputs on the contributions of Prof. Salimuzzaman Siddiqui in Pakistan.

\section{BiBLIOGRAPHY}

Akhtar, M. Salimuzzaman Siddiqui, M B E, F R S, Biogr. Mems Fell. R. Soc., 42 (1996):401-417

Anand, N; Bindra, S J and Ranganathan, S. Art in Organic Synthesis, Holden Day, 1970.

Atma Ram, 14 ${ }^{\text {th }}$ Founder Memorial Lecture of Sri Ram Institute of Industrial Research, Delhi, 1978

Baker, W. Molecular rearrangement of some oacyloxyacetophenones and the mechanism of the production of 3-acylchromones, J. Chem. Soc. (1933): 1381-1389.

Chakraborty, S and Saha, C. A Tribute to Bardhan and Sengupta Synthesisers of Phenanthrene and its Derivatives, Resonance, (2015): 628-642.

De, A. Asima Chatterjee: A unique natural products Chemist, Resonance, 1 (2015): 6-22. doi:10.1007/ s12045-015-0148-9.

Goswami, S and Bhattacharya, S. Chemical Research of Sir Prafulla Chandra Ray, Resonance. 2001, http:/www.ias.ac.in/article/fulltext/reso/006/01/00420049 .

Krishnaswamy, N R. Professor T R Seshadri - An Acharya par excellence, Resonance, 9. 2, (2004): 35. doi:10.1007/BF02834954.

Mahal, H S and Venkataraman, K. Synthetical experiments in the chromone. group. XIV. Action of sodamide on 1-acyloxy-2-acetonaphthones, J. Chem. Soc. (1934): 1767-1769.

Mao, A A; Hynniewta, T M and Sanjappa, M. Plant wealth of Northeast India with reference to ethnobotany, Ind. J. Tradit. Knowledge. 8.1 (2009): 96-103.

Nagarajan, K. History of Natural Products Chemistry in India, Indian Journal of History of Science, 49.4 (2014): 377-398.

NIIR Board of Consultants, Handbook on Unani Medicines with Formulae, Processes, Uses and Analysis, Asia Pacific Business Press, New Delhi, 2003.

Nitya Anand. Krishnaswami Venkataraman, in Biographical Memoirs, INSA, Vol. 20 (1981):45-165.

Rangaswami, S. Tiruvenkata Rajendra Seshadri, in Biographical Memoirs, INSA, Vol.7 (1975): 101-167.

Shankar, R; Lavlekar, G S; Deb, S and Sharma, B K. Traditional Healing Practice and Folk Medicines used by the Mishing Community of North East India. $J$. Ayurved. Integrative Med., 3.3 (2012): 124-129.

Siddiqui, S and Siddiqui, R H. Chemical examination of the roots of Rauwolfina serpentina, J. Ind. Chem. Soc., 8 (1931): 667-80.

Siddiqui, S and Siddiqui, R H. The alkaloids of Rauwolfina serpentina, Part I. Ajmaline series. J. Ind. Chem. Soc., 9 (1932): 1-539.

Siddiqui, S and Siddiqui, R H. The alkaloids of Rauwolfina serpentina, Part II. Ajmaline series. J. Ind. Chem. Soc., 12 (1935): 1- 37.

Siddiqui. S. A note on the isolation of three new bitter principles from the neem oil, Current Science, 11 (1942): 278-279.

Singh, H. Ram Nath Chopra (1882-1973) - a visionary in pharmaceutical science. Indian Journal of History of Science, 43.2 (2008):231-264.

Valiathan, M S. Ayurvedic Inheritance: a Reader's Companion, Manipal Universiy Press, Manipal, India, 2013.

Venkataraman, K. The Chemistry of Synthetic Dyes, Volumes 1-8, Academic Press, New York, 1952-1974.

Venkataraman, K. The Analytical Chemistry of Synthetic Dyes, Wiley- Interscience, 1977. 